\title{
Design and Fabrication of Impact Strength Machine
}

\author{
Aliemeke B. N. G. Ehibor O. G. \\ Department of Mechanical Engineering, Auchi Polytechnic, Auchi
}

\begin{abstract}
The development of the impact strength testing machine is successfully presented. The impact strength testing machine is necessary for ascertaining the strength of metallic components in withstanding applied load. A comprehensive design analysis was carried out to ascertain the various component sizes of the Impact strength testing machine in order to create a path for precise construction. Majority of the materials used in this fabrication were obtained locally. The constructed machine yielded a maximum velocity of $4.9 \mathrm{~m} / \mathrm{s}$ on execution of Charpy and Izod impact test. Great stability was achieved as a result of thick base plate and column support used during construction. A crushing force of $68.05 \mathrm{KN}$ and an impactor head energy of about 35J was able to impart the requisite deformation on the metallic specimen needed for the Charpy and Izod tests.
\end{abstract}

Keywords: Impact strength, Design, Construction, Crushing force

DOI: $10.7176 / \mathrm{JIEA} / 11-2-01$

Publication date: April $30^{\text {th }} 2021$

\section{Introduction}

Impact strength is the resistance offered by a material in response to an applied load. The fracture toughness of an engineering material is a very important property (Habibah et al., 2015). The purpose of the impact test machine is to measure toughness of materials. Metallic materials when they fail tend to fail in a catastrophic way (Sekar et al., 2013). Unlike metals they suddenly fail with little yielding before totally collapsing. So it is very important we have a good idea of the minimum impact force needed to induce a crack into the material (Avalle et al., 2002). The main application of this impact testing machine is to determine material toughness or impact strength during loading conditions on the test specimen (Shende et al. , 2015). An impact test is a dynamic test in which the selected specimen is usually notched to a stuck and broken in a single blow (Anmol et al., 2017). The test can be used for determining the shock absorbing ability of a particular composition of material so that its proper application could be decided (Hassan \& Bukar, 2009). This work presents the development of an impact testing machine.

In a bid to examine the effect of mechanical properties on metallic components, Akhil et al, 2016) investigated the ultimate yield strength and impact strength of Silumin using an impact strength machine. The study showed that the aluminium alloy exhibited very high ultimate yield strength of about 1300Mpa when compared to other aluminium alloy and composites.

Mathai et al. (2015) investigated the effect of alloying elements on the impact strength of Aluminium-silicon piston alloys. The needle shaped silicon in the structural matrix of Al-Si alloys exhibits improved mechanical properties when heat treated in the presence of various alloying elements. The study investigates the effect of silicon on the hypoeutectic, eutectic and hypereutectic aluminium piston alloys. The result of the study revealed that higher Si content of the hypereutectic piston alloy contributes to the high ultimate tensile strength and hardness of aluminium silicon alloys. It also reveals that mechanical properties increase with silicon content.

An increase in fatigue and impact strength of engine components was reported in Durowoju et al. (2014). The cast aluminium alloy piston from a sand casting process had its silicon morphology modified by antimony. The silicon platelets of the melted scraps displayed bigger particles when compared with the modified cast aluminium alloy piston. The result of the study showed that the refined microstructure of the modified cast aluminium may have stimulated an increase in tensile and fatigue strength.

A study which inferred that fatigue failure occurs in metallic components when subjected to fluctuating or cyclic loading was examined by Avalle, et al. (2002). The study established that when fatigue failure of engine components are not actually predicted by engineers and designers it may impede on working plan of an entire mechanical system.

The challenge to develop local content in the design and construction of relevant laboratory equipments has been a bane in research breakthrough in Nigeria. Some of the imported laboratory equipments come with incomprehensive manuals and numerical codes which are difficult for our technologists to apply. All these hinder the rate of technology transfer. This present study will address these shortcomings by developing indigenous capacity in the design and construction of Impact testing machine

The benefit of the present design is the simplicity of its modeling and ease of understanding. The impact specimen will be modeled as a simply supported beam. The machine will enable the evaluation of the toughness roughness characteristics of the material analyzed by plotting a graph of breaking stress against time taken. An affordable and a fully functional educational version of the Impact Testing apparatus that produces dependable 
results will be achieved.

The study will promote indigenous capacity in the design and construction of an Impact strength testing machine. Also, adequate determination of the Impact strength of aluminium alloys and steel materials will be effectively carried out before been applied in machine design and assembly.

The aim of this research is to design, fabricate and evaluate the Impact Strength Testing machine. The objectives pursued in this study were

i. Selection of appropriate materials for the design

ii. Determination of parts of the machine using mathematical and Engineering formulae

iii. Development of adequate graphical modelling

iv. Determination of performance evaluation on Impact machine using aluminium and steel specimens

\section{Materials and Methods}

The materials used in this study were sourced locally. The machine was developed as a facility to provide experimental data of impact loads on the metallic specimens that absorbed kinetic energy during collision (Martin et al.,2016). Material standard was considered while developing the machine. The modeling of the set up was done using Autodesk 3D software. Fabrication and construction was carried out at relatively low cost to produce functional equipment. The equipment is equipped with load cell measuring scale to detect the impact load on the specimen and the result of impact is digitally shown (Anmol et al. , 2017).

In addition the design and fabrication of the machine was carried out in Auchi Polytechnic Mechanical Engineering Workshop, Auchi.

\subsection{Design specifications for the Impact testing machine}

i. Total length of the guide columns is $1.5 \mathrm{~m}$

ii. Maximum dropping height is $1.2 \mathrm{~m}$

iii. Impactor head weight is $3 \mathrm{~kg}$

iv. $\quad 500 \mathrm{~kg}$ load cell with precision of 0.01

\subsection{Determination of crushing force required by the impactor}

The crushing force required for impact can be determined using equation (1)

$$
F=P_{i} \times A_{S}
$$

Where $\mathrm{F}=$ crushing force $(\mathrm{N})$

$\mathrm{P}_{\mathrm{i}}=$ Maximum operating crushing pressure $\left(\mathrm{N} / \mathrm{mm}^{2}\right)$

$\mathrm{A}_{\mathrm{s}}=$ Surface area of impact specimen

For an impact specimen of diameter $50 \mathrm{~mm}$ the surface area of the specimen is calculated to be $0.019636 \mathrm{~m}^{2}$.

Applying a maximum crushing pressure of $35.00 \mathrm{~N} / \mathrm{mm}^{2}$ the crushing force becomes

$$
F=35.00 \times 1963=" 00068.705 K N
$$

\subsection{Design for Support size}

The supports are columns which connect the top plate and the base plate. For this study the 4 metal supports were used. The force acting on each support is as given in equation (2)

$$
F_{S}=\frac{F}{4}
$$

Where $\mathrm{Fs}=68.705 \mathrm{KN}(\mathrm{N})$

The force acting on each support is

$$
F_{s}=\frac{68705}{4}=17.18 \mathrm{KN}
$$

The diameter of the support is determined equation (3)

$$
d_{s}=\sqrt{\frac{4 K F_{s}}{\pi \sigma}} \quad: t
$$

Where ds $=$ diameter of support $(\mathrm{m})$

$$
\mathrm{K}=\text { factor of safety }(1.5)
$$

$\sigma=$ yield stress of support material(high strength alloy steel $690 \mathrm{MPa}$ )

$d_{s}=\sqrt{\frac{4 \times 1.5 \times 17180}{3.142 \times 690}}=6.90 \mathrm{~mm}$ 
The diameter of the support was determined to be $6.90 \mathrm{~mm}$

\subsection{Determination of the Top plate thickness}

The thickness of the top plate is determined using equation (4)

$$
t_{p}=\sqrt[3]{\frac{0.0284 W b^{4}}{E \delta}\left[\frac{1}{1.056\left(\frac{b}{a}\right)^{5}+1}\right]}
$$

Where $t_{p}=$ thickness of top plate $(\mathrm{mm})$

$\mathrm{E}=$ Modulus of elasticity of top plate steel material (200000Mpa)

$\mathrm{a}=$ length of plate $(225 \mathrm{~mm})$

$\mathrm{b}=$ width of plate $(450 \mathrm{~mm})$

$\mathrm{W}=$ uniform distributed load $(\mathrm{N})$

$\delta=$ maximum deflection

The uniform distributed load was taken to $70 \mathrm{KN}$ which is the value of the crushing force finally used in this study from a calculated value of $68 \mathrm{KN}$. While the maximum deflection was determined to be $1 / 360$ of $10 \%$ of the crushing force determined. The thickness of the top plate is determined to be

$$
t_{p}=\sqrt[3]{\frac{0.0284 \times 70000 \times 450^{4}}{200000 \times 19.444}\left[\frac{1}{1.056\left(\frac{450}{225}\right)^{5}+1}\right]}=18.11 \mathrm{~mm}
$$

\subsection{Determination of Base plate thickness}

The thickness of the base plate of the impact strength testing machine is determined using equation (5) as given by (Eugene \& Theodore, 1999). The base frame is shown in Figure 1.

$t_{b}=\sqrt{\frac{C F_{c} b^{2}}{E_{b} \delta}}$

Where $\mathrm{t}_{\mathrm{b}}=$ thickness of base plate $(\mathrm{mm})$

$\mathrm{E}_{\mathrm{b}}=$ Modulus of elasticity of base steel plate material (200000Mpa)

$\mathrm{b}=$ breadth of plate

$\mathrm{F}_{\mathrm{c}}=$ concentrated load

$\mathrm{C}=$ constant that depends $\mathrm{b} / \mathrm{a}$

The concentrated load was taken to be half of the determined crushing force (Hassan and Bukar, 2009). The thickness of the base plate was determined to be

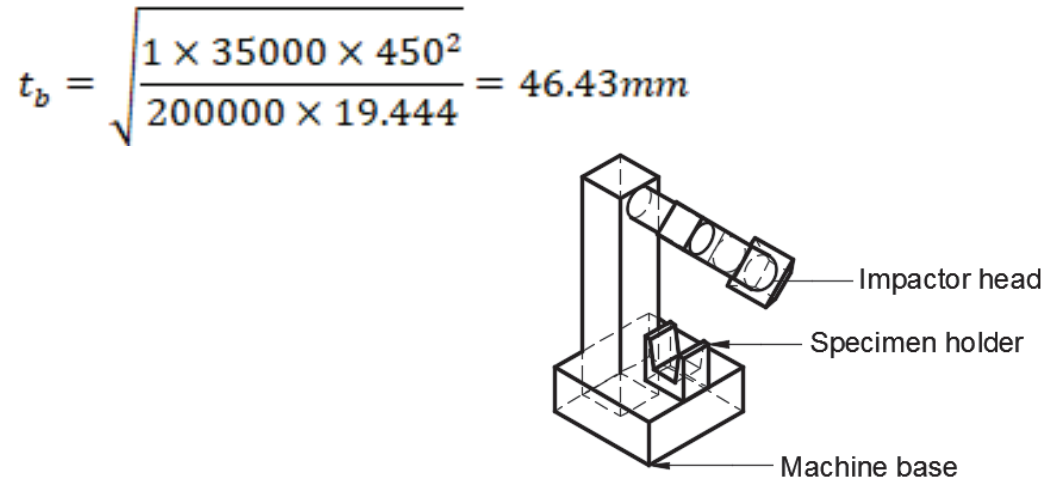

Figure 1:Machine base and specimen holder frame

\subsection{Determination of impact velocity}

The impact energy testing machine works on the principle of free fall (Maca et al., 2014). The impact velocity can be determined using equation (6) (Sharma \& Aggarwal, 2012)

$V=\sqrt{2 g h}$ 
Where $\mathrm{V}=$ impact velocity

$$
\begin{aligned}
& \mathrm{g}=\text { acceleration due to gravity }\left(\mathrm{m} / \mathrm{s}^{2}\right) \\
& \mathrm{h}=\operatorname{drop} \text { height }(\mathrm{m})
\end{aligned}
$$

The velocity was determined to be

$V=\sqrt{2 \times 9.81 \times 1.2}=4.85 \mathrm{~m} / \mathrm{s}$

\subsection{Determination of Impactor head energy}

The maximum energy stored in an impactor head is its potential energy which is given as the energy that can be absorbed by the metal specimen to be fractured. The maximum energy stored is calculated using equation (7) as applied in Sharma \& Aggarwal (2012).

$$
E=m g h \quad 000
$$

Where $\mathrm{E}=$ potential energy

$$
\mathrm{m}=\text { mass of impactor head }(\mathrm{kg})
$$

The maximum potential energy stored was determined to be $E=3 \times 9.81 \times 1.2=35.32 \mathrm{~J}$

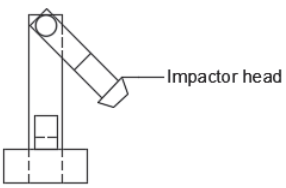

Figure 2:Frame bearing Impactor head

\subsection{Determination of the weight of the Impact strength machine}

The entire weight of the whole assembly is determined using equation (8)

$W_{T}=W_{f}+W_{l}+W_{h}+W_{s}$

Where $W_{T}=$ Entire weight of the impact strength mchine

$\mathrm{W}_{\mathrm{f}}=$ weight of frame

$\mathrm{W}_{1}=$ weight of load cell

$\mathrm{W}_{\mathrm{h}}=$ weight of impactor head

$\mathrm{W}_{\mathrm{s}}=$ weight of specimen

The entire weight of the machine was determined to be

$$
W_{T}=100+50+3.0+5.0=168 \mathrm{Kg}
$$

\section{Results and discussion}

\subsection{Modelling of the Impact Strength Machine}

The graphical modeling of the impact strength testing machine was done using Autodesk AUTOCAD 2016. The isometric view, orthographic drawing and the constructed frame of the achine are shown in Figures 3, 4 and 5 respectively.

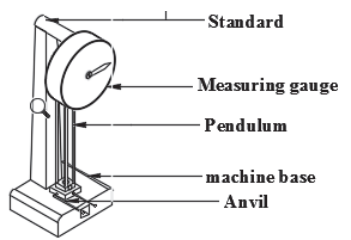

Figure 3: Isometric view of the Impact strength testing machine 

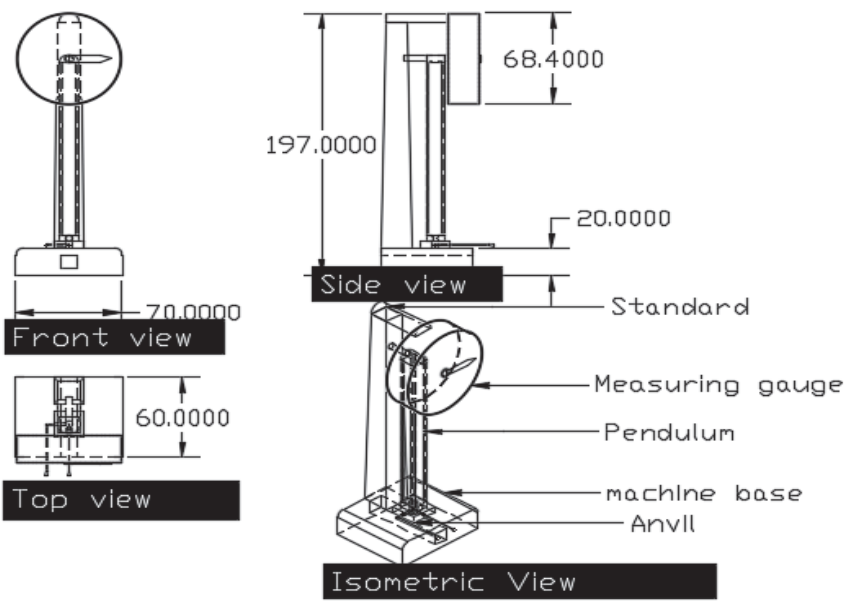

Figure 4:First Angle Orthographic Projection of the Impact strength machine

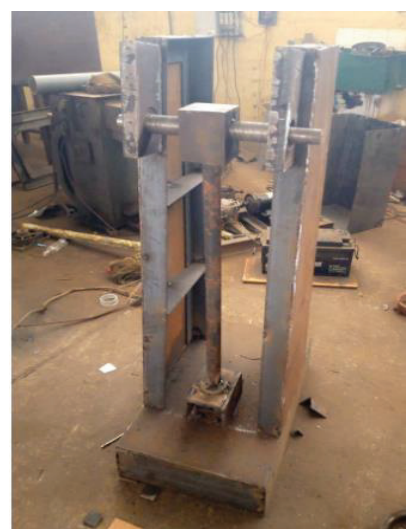

Figure 5: Constructed frame of the Impact Strength Machine

\subsection{Summary of the impact strength machine parameters}

The designed parameters of the machine are summarized in Table 1.

Table 1: Summary of Design Parameters

\begin{tabular}{|l|l|l|}
\hline $\mathrm{S} / \mathrm{N}$ & Parameter & Determined value \\
\hline 1 & crushing force & $68.705 \mathrm{KN}$ \\
\hline 2 & Force on each support & $17.18 \mathrm{KN}$ \\
\hline 3 & Diameter of support & $6.90 \mathrm{~mm}$ \\
\hline 4 & Top plate thickness & $18.11 \mathrm{~mm}$ \\
\hline 5 & Base plate thickness & $46.43 \mathrm{~mm}$ \\
\hline 6 & Impact velocity & $4.85 \mathrm{~m} / \mathrm{s}$ \\
\hline 7 & Impactor head energy & $35.32 \mathrm{~J}$ \\
\hline 8 & Weight of machine & $168 \mathrm{Kg}$ \\
\hline
\end{tabular}

\subsection{Construction of the Impact Strength Testing machine}

The Impact strength testing machine was constructed by applying the determined values of the various components as shown in Table 1. The base and top of the machine was constructed with a steel plate of $46 \mathrm{~mm}$ and $18 \mathrm{~mm}$ thickness respectively. A great thickness of the base plate is essential so as to withstand the weight of the load cell. The support connection between the top plate and the machine base was fabricated with $5 \mathrm{~mm}$ angle bar. An impactor head was attached or screwed to the rod which has the tendency to swing transversely. A load cell was built into the machine to help create electrical signals whose magnitude is directly proportional to the force been applied. 


\subsection{Conclusion}

The development of the impact strength testing machine was successfully executed. The constructed machine yielded a maximum velocity of $4.9 \mathrm{~m} / \mathrm{s}$ on execution of Charpy and Izod test. Great stability was achieved as a result of thick base plate and column support used during construction. A crushing force of $68.05 \mathrm{KN}$ and an impactor head energy of about $35 \mathrm{~J}$ was able to impart the requisite deformation of the metal specimen needed for the Charpy and Izod tests. It was also noticed from the study that an increase of crushing force brought about an increase in the impact energy a finding which was also in consonance with the result obtained in Navarrete et al. (2004)

\subsection{Conflict of interest}

The authors of this article have not declared any conflict of interest.

\subsection{Acknowledgement}

The authors of this article would like to appreciate the Management of Tertiary Education Trust Fund (TETFund), Abuja and Auchi Polytechnic, Auchi for providing the needed fund for this profound research. This type of collaboration and assistance is necessary for sustainable development at the tertiary education level in Nigeria.

\section{References}

Akhil, T., Naresh, K., Khurshid, A. \& Kumar, P.A. (2016). Analysis on Four Stroke Single Cylinder Engine Piston by using Aluminium Alloys (AI - GHS 1300, Al-SiC-Graphite A6061 Pure Aluminium). International Journal of Mechanical engineering, Vol. 3, No. 1, pp. 4 - 13.

Anmol S. , Karthik D., Hemanth K. J. \& Naveen H. E.(2017). Design and Fabrication of Drop Weight Impact Strength Testing Machine, Imperial Journal of Interdisciplinary Research, Vol. 3, No. 6, pp. 1121-1128.

Avalle, M. ,Belingardi, G. \& Cavatorta, M. (2002). Static and fatigue Strength of a Die Cast

Aluminium Alloy Under Different Feeding Conditions, International Journal of Fatigue, Vol. 1, No. 24, pp. 1-9

Durowoju, M.O. ,Babatunde, I.A., Raheem, W.A. \& Ajala, M.T. (2014). Effect of Antimony on the Tensile Strength and the Morphology of Si Platelets in Recycled Aluminium Pistons Alloys. Journal of Material Science and Engineering, Vol. 3, No. 2 pp. $1-6$.

Eugene A., \& Theodore B. (1999). Marks Standard Handbook for Mechanical Engineers $10^{\text {th }}$ Edition, Mc-Graw Hills Companies, Inc.

Habibah N., Faizal, W. M., Iamie M. , Izzatic N. \& Hasni N., (2015). Design and Development Drop Weight Impact Test Rig, 2nd Integrated Design Project Conference, University of Malaysia, Pahang, pp. 1-9.

Hassan A. B. \& Bukar Y. A. (2009). Design and Fabrication of a Compression Strength Testing Machine for Blocks and Clay Bricks, Leonardo Electronic Journal of Practices and Technologies, Vol. 10, No. 14, pp. 142-153.

Maca P. , Zatloukal J. \& Sovjak R. (2014), Design of a Novel Horizontal Impact Machine for

Testing of Concrete Specimens, WIT Transactions on the Built Environment, Vol. 141, No. 10, pp. 150-160.

Martin K. V. , Vipin V. V. \& Suneeth S. (2016), Fabrication and Analysis of Fatigue Testing Machine, The International Journal of Engineering and Science, Vol. 5, No. 7, pp. 15-19.

Mathai, B., Mathew, C. , Pratheesh, K. \& Varghese, C.K. (2015). Effect of Silicon on Microstructure and Mechanical Properties of Al-Si Piston Alloys, International Journal of Engineering Trends and Technology, Vol.29, No.6, pp.299-305.

Navarrete M. , Godinez F. A. \& Serrania F. , (2004). Design and Fabrication of a Low Speed Impact Tester, Journal of Applied Research and Technology, Vol. 2, No. 3, pp. 249-254.

Sekar K. , Allesu K. \& Joseph M. A. (2013). Design, Construction and Performance Evaluation of Multiple Casting Machine, Nigerian Journal of Technology, Vol. 32, No. 3, pp. 498-506.

Sharma, P. C. \& Aggarwal, D. K. (2012). A Textbook of Machine design. Twelfth Edition, S. K. Kataria and Sons, Daryaganj, New Delhi, India

Shende C. J., Sahu A. R. \& Deshmukh A. V. (2015). Modelling and Analysis of Hammer of Impact Testing Machine, International Journal of Mechanical Engineering and Robotics Research, Vol. 4, No. 1, pp. 350354. 